-REVIEW ARTICLE

Volume 12 Issue 22020

DOI: 10.21315/eimj2020.12.2.2

ARTICLE INFO

Submitted: $16-2-2020$

Accepted: $16-3-2020$

Online: 30-06-2020

\section{Reframing Resilience Concept: Insights from a Meta-synthesis of 21 Resilience Scales}

\author{
Majed Mohammed Wadi ${ }^{1,2}$, Nadia Izzati Nordin², Nurhanis Syazni \\ Roslan'2, Tan Celina ${ }^{2}$, Muhamad Saiful Bahri Yusoff ${ }^{2}$ \\ ${ }^{1}$ College of Medicine, Qassim University, SAUDI ARABIA \\ ${ }^{2}$ School of Medical Sciences, Universiti Sains Malaysia, \\ Kelantan, MALAYSIA
}

To cite this article: Wadi MM, Nordin NI, Roslan NS, Celina T, Yusoff MSB. Reframing resilience concept: insights from a meta-synthesis of 21 resilience scales. Education in Medicine Journal. 2020;12(2):3-22. https://doi.org/10.21315/eimj2020.12.2.2

To link to this article: https://doi.org/10.21315/eimj2020.12.2.2

\title{
ABSTRACT
}

In general context, resilience refers to individuals' ability to adapt to significant adversities while maintaining good mental and physical well-being. Over the past three decades, resilience paradigm has evolved from a stable trait-oriented approach to process-oriented or outcome-oriented approach. However, robustness of resilience conceptualisation is still scant. Review of the common characteristics of resilience across validated resilience scales were conducted. Several databases were searched, and several keywords were used. Articles that fulfill the predetermined criteria were selected. Twenty-one original articles describing resilience were selected. A thematic approach was performed to categorise common patterns or characteristics shared across the scales that later form emerging constructs representing resilience. Constructs were grouped according to similar attributes, elements, and themes underlying resilience. Four emerging themes were identified; control, resourceful, growth, and involvement. The constructs from the 21 selected scales were mapped against the four emerging themes. Additionally, they are marked as either as exclusive or shared constructs. The relationship between the four emerging themes were determined considering two continuums (present and past) and two conditions (internal and external). Hence, the integrated resilience model was proposed to conceptualise the relationships of the four emerging resilience themes. The integrated resilience model is a promising model that can be used for different practical implications. It can be used to build new measurement scale, nurturing resilience in medical and health professions education and infusing resilience in the assessment practice.

Keywords: Resilience, Burnout, Well-being, Health profession education, Medical education, Resilience scales

Majed Mohammed Wadi, School of Medical Sciences, Universiti Sains Malaysia, 16150 Kubang Kerian, Kelantan, Malaysia and College of Medicine, Qassim University, Saudi Arabia | Emails: m.wadi@qu.edu.sa and majed_wadi@yahoo.com

\section{INTRODUCTION}

"Of all the virtues we can learn, no trait is more useful, more essential for survival, and more likely to improve the quality of life than the ability to transform adversity into an enjoyable challenge", Mihaly Csikszentmihalyi (1).
From this notion, resilience in general context refers to individuals' ability to adapt to significant adversities while maintaining good mental and physical wellbeing (2). There are different definitions and conceptualisations of resilience (3-5). In general, resilience is a person's ability 
to cope and deal with adversity effectively and positively, thus improving the person's well-being (3-8).

Over the past three decades, resilience paradigm has evolved from a stable traitoriented approach to process-oriented or outcome-oriented approach (9). It has been viewed as amenable (10) and could be partially predicted by several unique factors depending on the resilience contexts. These factors can be broadly categorised into demographic variables such as gender, and psychological variables such as depression (risk factors) and support (protective factor). However, no single predictor has been identified to impose dominant influence on resilience formation (11). Therefore, the view of resilience as a stable trait has become less accepted as it does not acknowledge the interaction between individuals, environment and faced adversities (4). The evolving understanding of resilience has also led to the term used interchangeably with hardiness, mental toughness, grit and retention (12). Despite this overlapping, various literature has concluded that resilience is not mere toughness, but also characterised by dynamic process of effective negotiation, adaptation and management of stressors (5, 13).

Resilience becomes a topic of interest in many sciences $(3,14)$ and has been studied under several areas such as developmental psychology, sociology, trauma, and medical education (15-18). Under the spectrum of healthcare professionals (HCP), it has additional concern due to the nature of the health professions workers where they are expected to promote the physical and mental health and well-being of others. Therefore, resilience is a critical attribute for them (19-20).

Modern HCP are faced with many stressors such as rising patient expectations, workforce shortage, clerical and bureaucracy demands, fear of making errors, practice litigation and poor reward system $(12,21-$ 22). Over the recent years, there has been an increasing amount of literature reporting a high prevalence of burnout ( $17 \%$ to $86 \%)$ among HCP (21, 23-25). To alleviate burnout syndrome among HCP, outlined strategies were not limited in reducing stressful stimuli. The postmodernist movement has also focused on building HCP capacity to cope with adversities such as in resiliency training (18-26). The latter strategies were supported by some evidence on its protective role against burnout and this has resulted in increased interest in resilience (27-28).

A meta-analysis by Leppin and colleagues revealed the lack of a unified view and consensus in resilience (13). Even with this concern, growing studies in HCP context have shown positive association between resilience and compassion satisfaction, patient care, and negative associations between resilience and burnout, secondary stress, anxiety, intolerance to ambiguity and communication (29). Despite the evidence on the lack of framework to guide intervention, many health institutions have still adopted or institute their own resilience interventions $(27,30)$. Common intervention strategies include psychosocial skills training, mindfulness, Stress Management and Resiliency Training (SMART), narrative and simulation training (31-34). These interventions have been shown effective with moderate positive effect (10). At the training level, more educational institutions have focused on resilience as part of essential competencies in producing work-ready candidates or trainees (35-36). The trends towards competency-based medical education have also led to resilience being considered as part of the assessment domain in medical training and even earlier in the student selection process (37). This calls for a solid understanding of the resilience concept in HCP context to ensure theoretical rationale in guiding education and intervention, and construct validity in assessment measurement. 
Although a number of scales have been developed for measuring resilience, they are not widely adopted and no scale is preferable over the others (38). Consequently, researchers and clinicians have little evidence to inform their choice of resilience measurement and may make an arbitrary and inappropriate selection for the population and context. Methodological reviews aim to identify, compare and critically assess the validity and psychometric properties of conceptually similar scales, and make recommendations about the most appropriate use for a specific population, intervention, and outcome. Fundamental to the robustness of a methodological review is the quality criteria used to distinguish the measurement properties of a scale to enable a meaningful comparison (39).

There is a scant review on resilience measurement scales. An earlier review of instruments measuring resilience compared the psychometric properties and appropriateness of six scales for the study of resilience in adolescents (40). Another review was done by Windle et al. (38), in which 15 resilience scales were evaluated against strong quality criteria to assess validity and reliability, however, the conceptual framework of resilience is not adequately addressed.

The common resilience scales used in HCP studies include the Brief Resilient Coping Scale (BRCS) and the Connor-Davidson Resilience Scale (CD-RISC) (36). However, it is interesting to note that none of these scales were explicitly developed for HCP context $(24,33,37)$.

We would wonder how robust resilience had been conceptualised to measure attributes that reflect the resilience concept. Given the increasing interest in resilience from various stakeholders, this article provides a new conceptual framework for a brief update on the emerging constructs of resilience based on a meta-synthesis of 21 selected resilience scales and identified several practical implications in the measurement of resilience in medical and health professions education.

\section{METHODS}

We conducted a review of the common characteristics of resilience across validated resilience scales. Several databases namely PubMed, CINAHL, PsycINFO and Google Scholar were searched to identify the original articles describing resilience measurements. Several keywords were used for advanced search such as [resilience or mental toughness or grit or hardiness or buoyancy] AND [scales or questionnaire or measurements]. Articles that fulfill the following criteria were selected: (i) articles published in peer-reviewed medium, (ii) using English language, (iii) nonreview articles, (iv) provide construct(s) of resilience measured by the scale/ questionnaire, and (v) full article accessible. The selection of papers was appraised by title, abstract and full text prior to the extraction of relevant information. In addition, the selection of papers was appraised based on the authors' experience and judgement. Relevant information was tabulated in a narrative synthesis table that includes scale, authors, year, domain and context (Table 1). A thematic approach was performed to categorise common patterns or characteristics shared across the scales that later form emerging constructs representing resilience.

\section{RESULTS}

Twenty-seven resilience scales were identified as summarised in Table 1 . Out of 27 , only 21 scales were selected whose constructs of resilience are being measured in the report. Table 1 shows the resilience scales that were used in general context and in specific contexts such as academics, patients, workplace settings, and with different age groups spanning from children (12 years old) to older adults (45 years old 


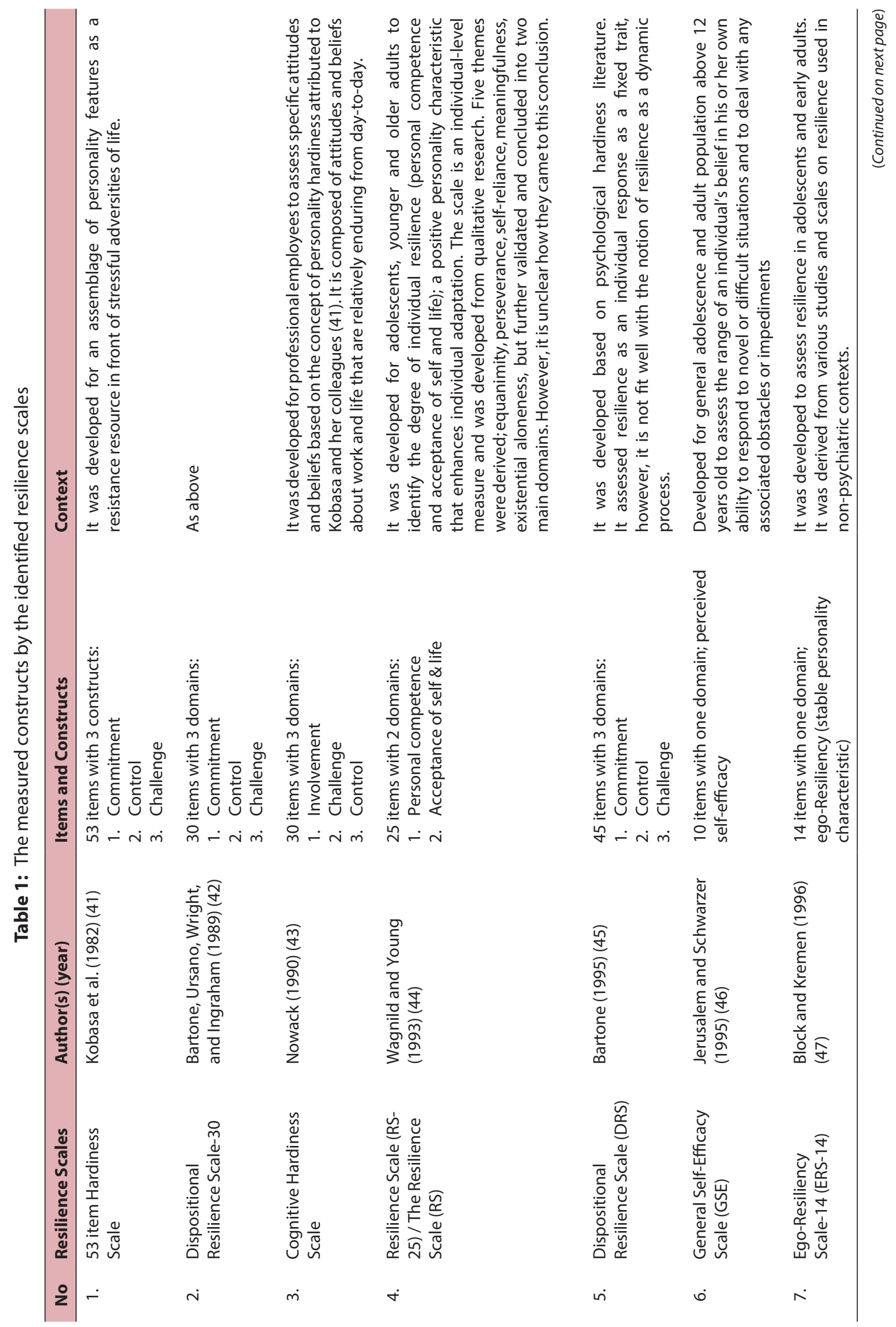




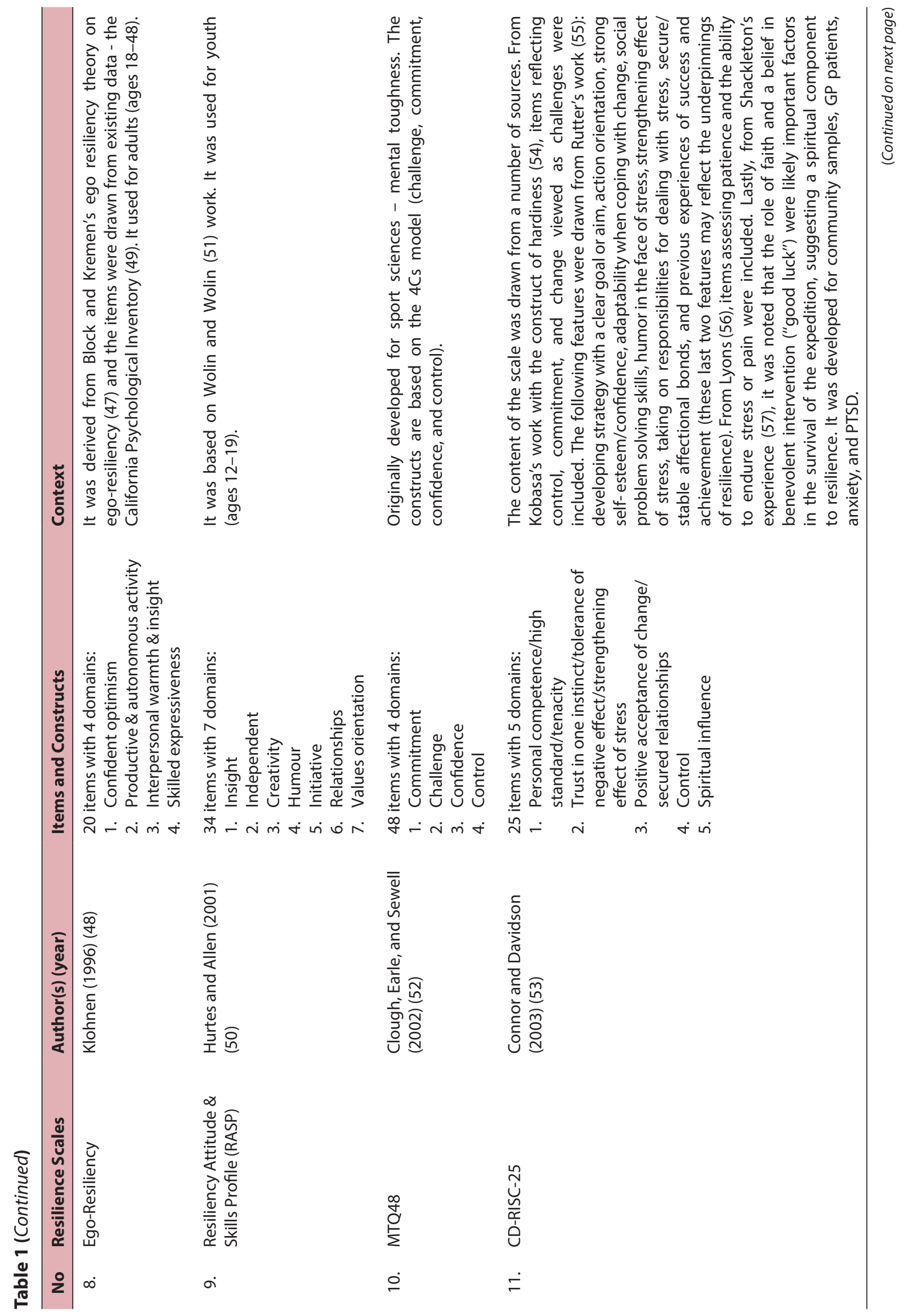




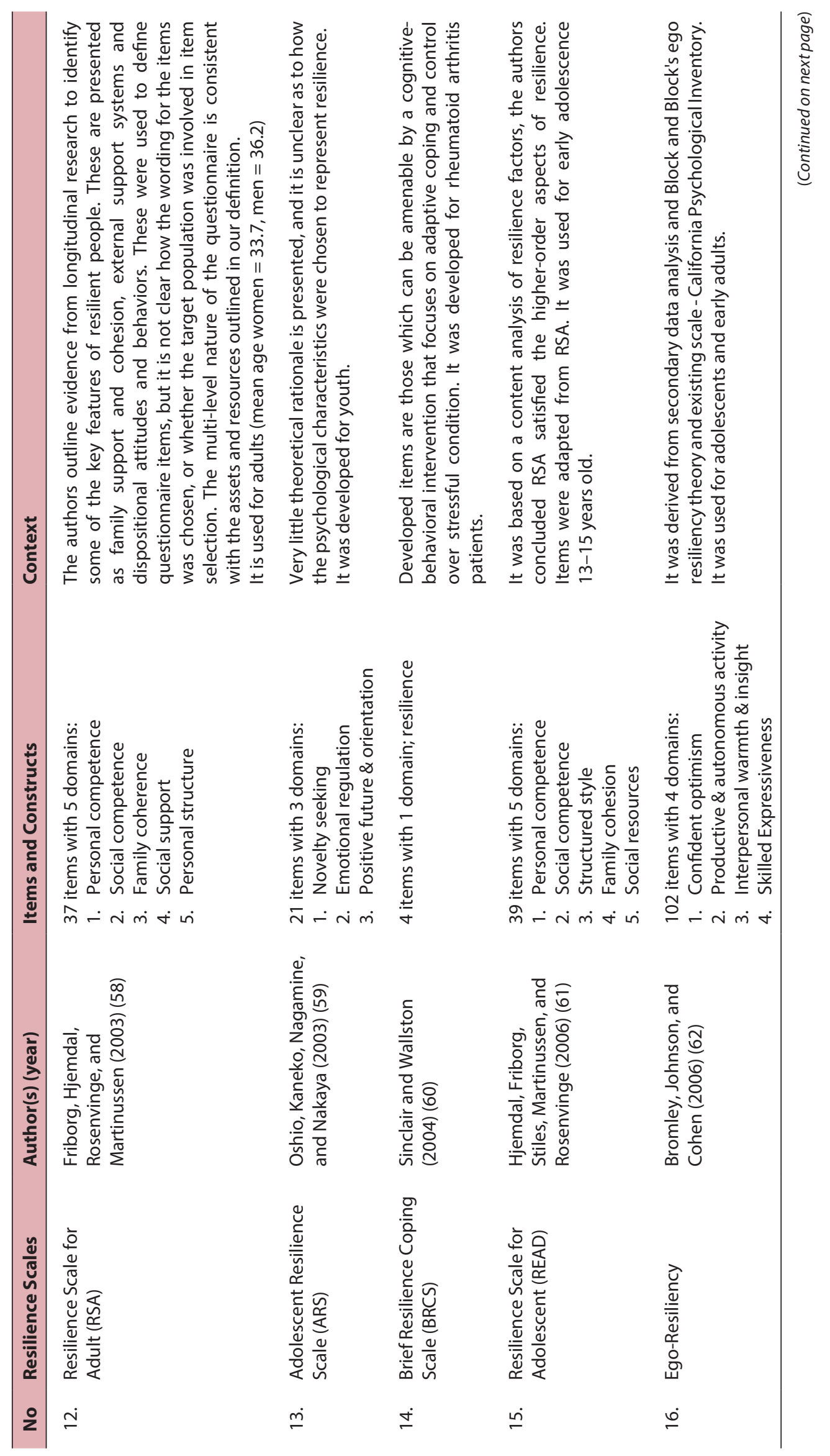



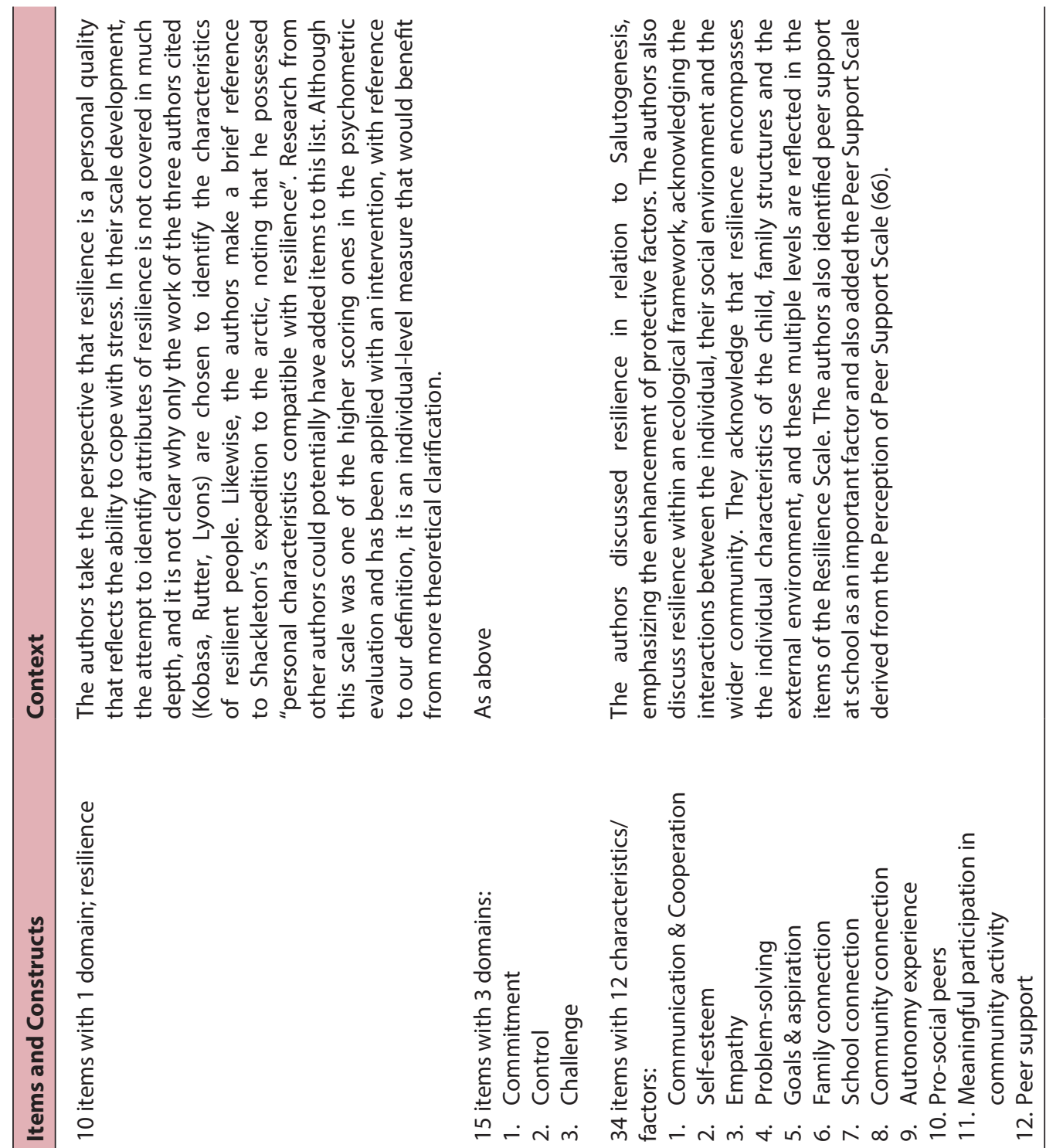

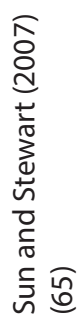

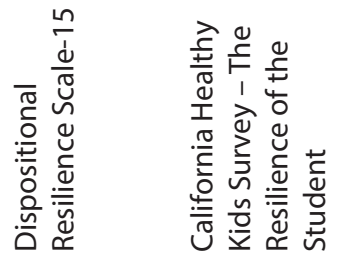

$\stackrel{\infty}{\sim}$

$\dot{9}$ 


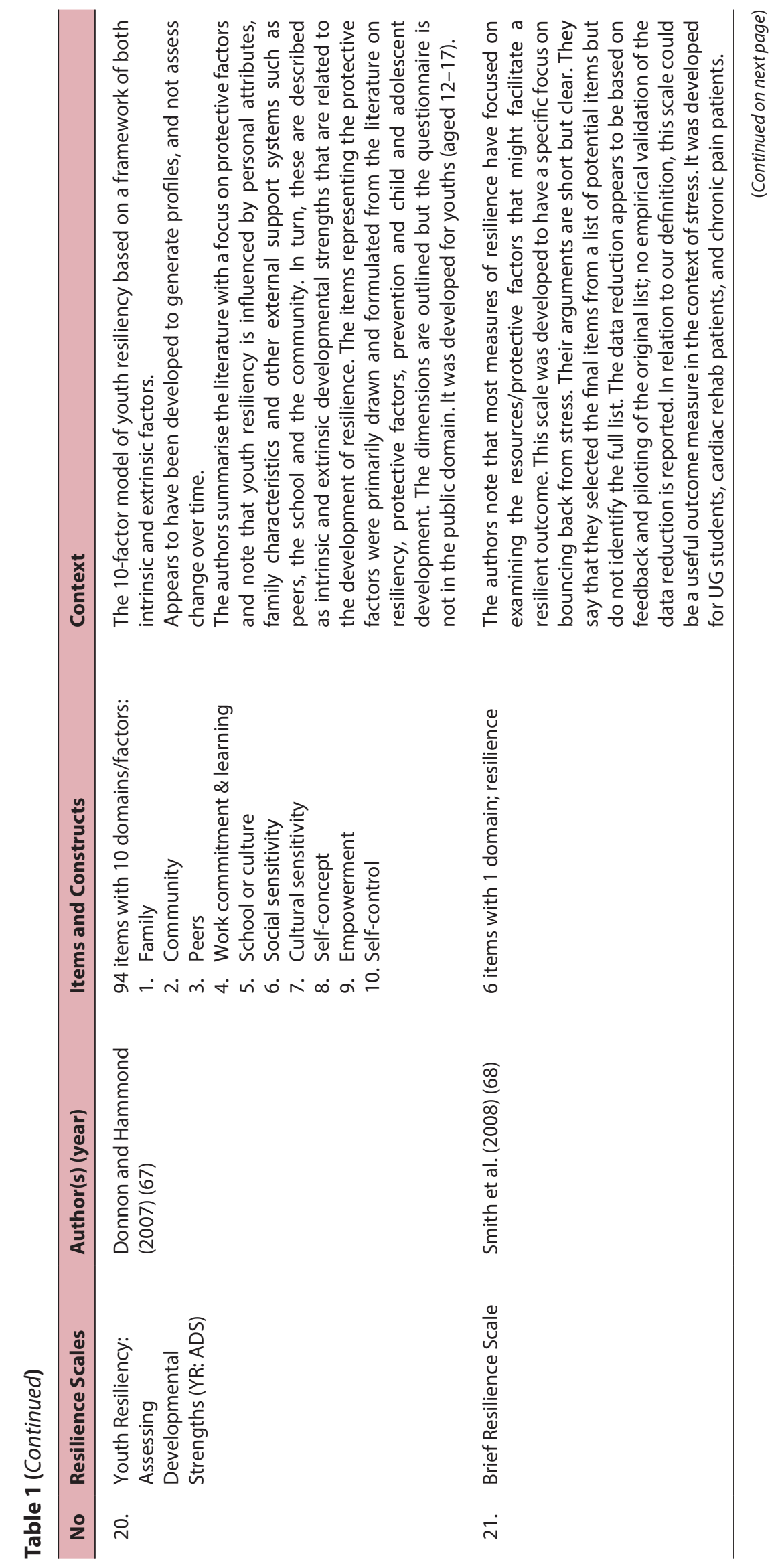




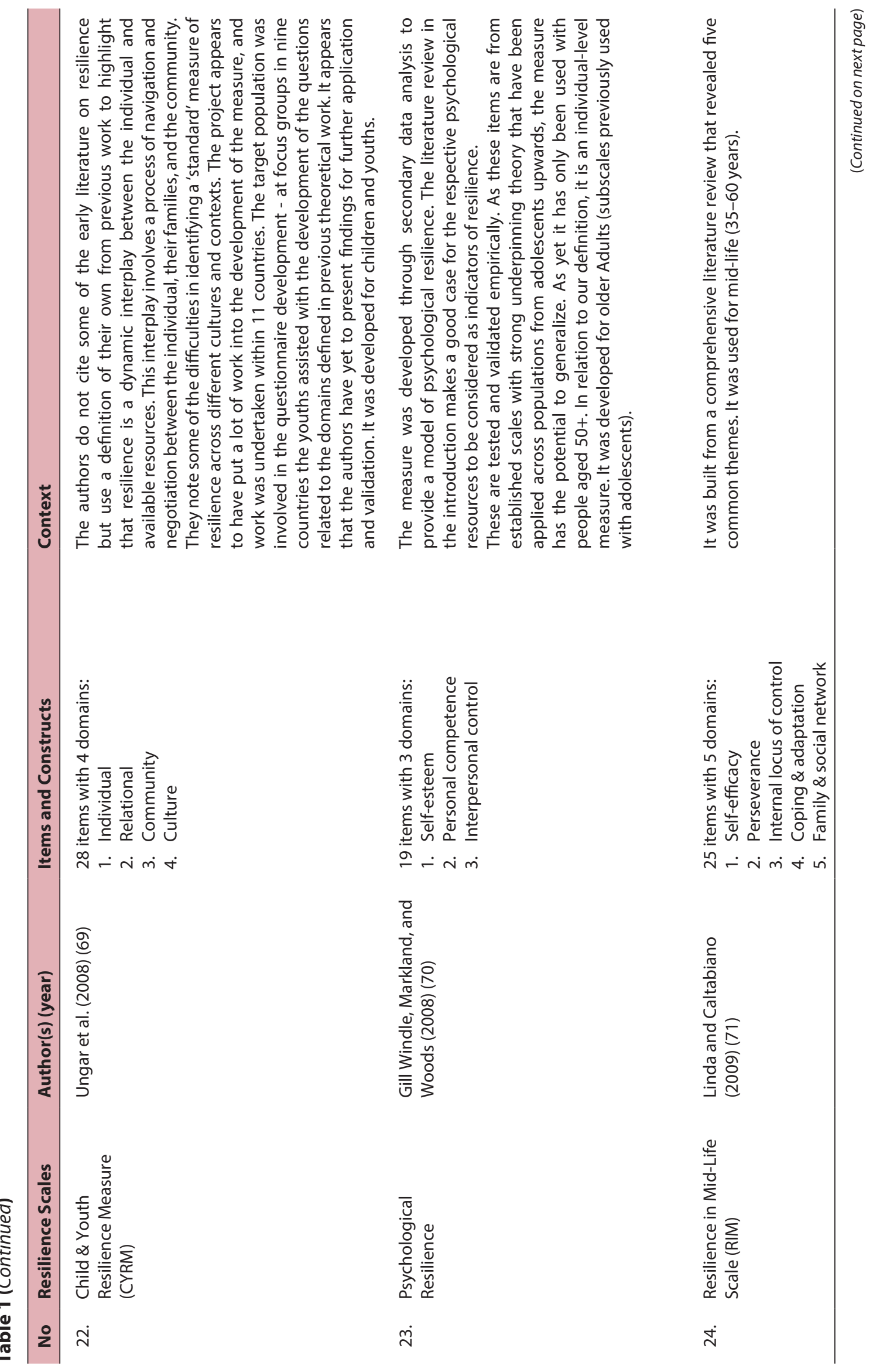




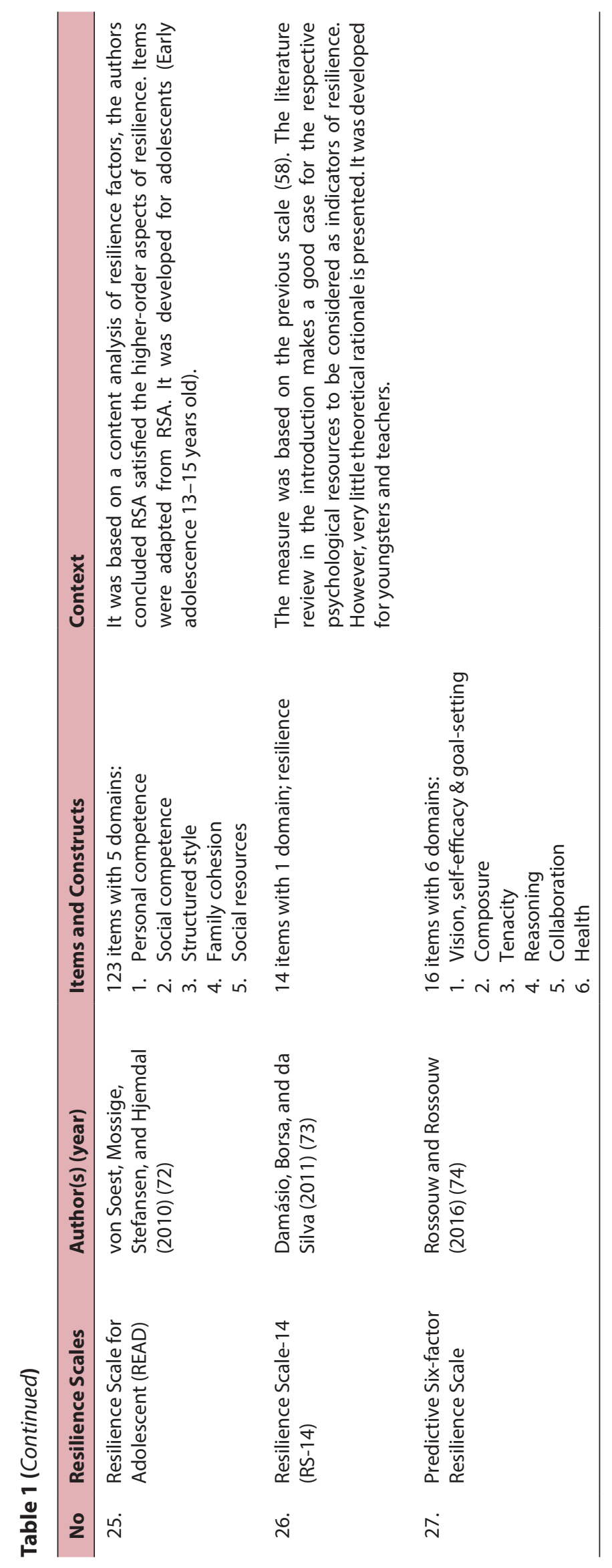


and above). Most scales were developed based on sound theoretical foundations specifically 4C model (commitment, challenge, confidence, control). We then undertook a thematic analysis of the identified resilience constructs, where only constructs that we perceived as relevant to resilience from each measurement tool are selected for our thematic analysis. We grouped constructs according to similar attributes. From this, we define each group that captured all relevant aspects as a newly emerging theme. We then discussed any construct of difference and agreed upon consensus, the elements, and themes underlying resilience. Based on thematic analysis of the constructs from 21 scales, four emerging themes were identified which are control, resourceful, growth, and involvement (Table 2). The mapping of 21 selected scales and the four emerging themes were summarised in Table 3.

Table 2 describes the four emerging themes (control, resourceful, growth, involvement) derived from the constructs of 21 selected scales. There are two forms of constructs namely exclusive constructs/ attributes and shared constructs/attributes. The exclusive attributes are referred to as those constructs that are limited to only one particular theme, in which the definition and application of the construct as provided by the original articles of respective resilience measurements/scales fit solely

Table 2: Thematic findings for Resilience Domain across 21 selected scales

\begin{tabular}{|c|c|c|c|}
\hline Themes & $\begin{array}{l}\text { Definition/description } \\
\text { of themes }\end{array}$ & $\begin{array}{l}\text { Exclusive attributes } \\
\text { (construct confined to } \\
\text { only } 1 \text { theme) }\end{array}$ & $\begin{array}{l}\text { Shared attributes } \\
\text { (between themes) }\end{array}$ \\
\hline Control & $\begin{array}{l}\text { Being composed and } \\
\text { controlled under } \\
\text { stressful adversity }\end{array}$ & $\begin{array}{ll}\text { 1. } & \text { Control } \\
\text { 2. } & \text { Composure } \\
\text { 3. } & \text { Tolerance of negative effect } \\
\text { 4. Internal locus of control } \\
\text { 5. Emotional regulation } \\
\text { 6. Interpersonal warmth \& } \\
\text { insight } \\
\text { 7. Interpersonal control } \\
\text { 8. Skilled expressiveness } \\
\text { 9. Humour } \\
\text { 10. } \\
\text { Self-esteem }\end{array}$ & $\begin{array}{ll}\text { 1. } & \text { Confidence } \\
\text { 2. } & \text { Self-efficacy } \\
\text { 3. } & \text { Perceived self-efficacy } \\
\text { 4. } & \text { Independent } \\
\text { 5. } & \text { Social sensitivity } \\
\text { 6. } & \text { Cultural sensitivity } \\
\text { 7. } & \text { Social competence } \\
\text { 8. } & \text { Self-concept } \\
\text { 9. } & \text { Confident optimism } \\
\text { 10. } & \text { Acceptance of self \& life } \\
\text { 11. } & \text { Positive acceptance of change } \\
\text { 12. } & \text { Productive \& Autonomous }\end{array}$ \\
\hline Resourceful & $\begin{array}{l}\text { Being able to find } \\
\text { appropriate solutions } \\
\text { from available resources } \\
\text { to deal with adversity }\end{array}$ & $\begin{array}{l}\text { 1. Trust in one instinct } \\
\text { 2. Personal competence/ } \\
\text { 3trength } \\
\text { 3. Creativity } \\
\text { 4. Problem-solving } \\
\text { 5. Social resources/ support } \\
\text { 6. Insight } \\
\text { 7. Novelty seeking }\end{array}$ & $\begin{array}{l}\text { 13. Initiative } \\
\text { 14. Self-control } \\
\text { 15. Communication \& cooperation } \\
\text { 16. Work commitment \& learning } \\
\text { 17. Positive future \& orientation } \\
\text { 18. Challenge } \\
\text { 19. Planned future }\end{array}$ \\
\hline Growth & $\begin{array}{l}\text { Keep growing and } \\
\text { bouncing back stronger } \\
\text { from the adversity }\end{array}$ & $\begin{array}{l}\text { 1. Empowerment } \\
\text { 2. Strengthening effect of stress } \\
\text { 3. Goals/goal setting \& } \\
\text { 4. Vision } \\
\text { 5. Coping \& adaptation }\end{array}$ & \\
\hline Involvement & $\begin{array}{l}\text { Being committed to } \\
\text { deal with the adversity }\end{array}$ & $\begin{array}{ll}\text { 1. } & \text { Commitment } \\
\text { 2. } & \text { Perseverance } \\
\text { 3. } & \text { Tenacity } \\
\text { 4. } & \text { Structured style/personal } \\
& \text { structure }\end{array}$ & \\
\hline
\end{tabular}


to that particular theme. For example, the "composure" construct from the Predictive Six-factor Resilience Scale is primarily about emotional regulation and the ability to recognise, understand, and act on internal prompts and physical signals (74). This fits well and is primarily relevant to the theme "control" which we describe as "being composed and controlled under stressful adversity".

On the other hand, constructs that belong to more than one theme is referred to as shared attributes which possess definitions and application that overlaps between themes. For example, the attribute "challenge" appears in several scales bearing a collective description as such: the extent to which individuals see change and setbacks as challenges rather than threats to security and survival, being more open to change while possessing attitudes with a kind of zest for life and living that leads one to perceive changes and challenges as exciting, viewing them as opportunities for growth and will actively seek them out and will identify problems as ways for self-development (41-45).

This is a prime example of an attribute that encompasses multiple themes, in this case it overlaps between the themes namely resourceful_ " "being able to find appropriate solutions from available resources to deal with adversity," growth - "keep growing and bouncing back stronger from the adversity," and involvement- "being committed to deal with the adversity".

Table 3: The emerging themes of resilience from the attributes described in 21 selected scales

\begin{tabular}{|c|c|c|c|c|}
\hline Research tool & Control & Resourceful & Growth & Involvement \\
\hline MTQ48 & $\star$ & $\checkmark$ & $\checkmark$ & $\star$ \\
\hline CD-RISC-25 & $\star$ & $\star$ & $\star$ & $\star$ \\
\hline Resilience Scale for Adult (RSA) & $\checkmark$ & $\star$ & $\checkmark$ & $\star$ \\
\hline Adolescent Resilience Scale (ARS) & $\star$ & $\star$ & & $\checkmark$ \\
\hline Resilience Scale for Adolescent (READ) & $\checkmark$ & $\star$ & $\checkmark$ & $\star$ \\
\hline Resilience Scale for Adolescent (READ) & $\checkmark$ & $\star$ & $\checkmark$ & $\star$ \\
\hline Ego-Resiliency & $\star$ & & $\checkmark$ & $\checkmark$ \\
\hline Ego-Resiliency & $\star$ & & $\checkmark$ & $\checkmark$ \\
\hline Resilience in Mid-Life Scale (RIM) & $\star$ & $\checkmark$ & $\star$ & $\star$ \\
\hline Dispositional Resilience Scale (DRS) & $\star$ & $\checkmark$ & $\checkmark$ & $\star$ \\
\hline Dispositional Resilience Scale-30 & $\star$ & $\checkmark$ & $\checkmark$ & $\star$ \\
\hline Dispositional Resilience Scale-15 & $\star$ & $\checkmark$ & $\checkmark$ & $\star$ \\
\hline 53 Item Hardiness Scale & $\star$ & $\checkmark$ & $\checkmark$ & $\star$ \\
\hline Resilience Scale (RS-25) & $\checkmark$ & $\star$ & $\checkmark$ & \\
\hline Resiliency Attitude \& Skills Profile (RASP) & $\star$ & $\star$ & & $\checkmark$ \\
\hline California Healthy Kids Survey - The Resilience of the Student & $\star$ & $\star$ & $\star$ & $\checkmark$ \\
\hline Youth Resiliency Assessing Developmental Strengths (YRADs) & $\checkmark$ & $\checkmark$ & $\star$ & $\checkmark$ \\
\hline General Self-Efficacy Scale (GSE) & $\checkmark$ & $\checkmark$ & & \\
\hline Cognitive Hardiness Scale & $\star$ & $\checkmark$ & $\checkmark$ & $\checkmark$ \\
\hline Psychological Resilience & $\star$ & $\star$ & & \\
\hline Predictive Six-factor Resilience Scale & $\star$ & $\checkmark$ & $\star$ & $\star$ \\
\hline
\end{tabular}

Notes: $\checkmark$ - the scale contains construct with overlapping themes

$\star$ - the scale contains construct exclusively to the theme 
Shared attributes pose a more comprehensive view of resilience, the constructs are relatively well-rounded and pulls the themes towards the center of the emerging themes constituting the conceptual framework of resilience in this article, proposed in Figure 1. There are 19 shared attributes that overlap between at least two or more themes in this emerged resilience concept.

Table 3 maps the constructs from the 21 selected scales against the four emerging themes. In general, the scales are well mapped to the four emerging themes either as exclusive or shared constructs.

Figure 1 illustrates the relationship between the four emerging themes with the two continuums of state (present and future) and condition (internal and external). The internal environment is composed of various elements present inside the organisation, that can affect or can be affected by, the choices, activities, and decisions of the organisation (75). External factors are things from outside an organisation that directly or indirectly influences it. Oftentimes, these external factors are outside of the control of organisation (76). The present state is a present set of circumstances (77). The future state is a set of circumstances that will come after the present or the things that will happen then (78).

\section{DISCUSSION}

Resilience scales are developed based on several constructs and are summarised in Table 1. The resilience scales were developed based on sound theoretical foundations, for example, the mental toughness scale MTQ48 is based on the $4 \mathrm{C}$ model (commitment, challenge, confidence, control), and the various resilience scales were used in different contexts, with control as the most common construct to be used in many of the scales listed.

Resilience is generally defined as mentioned above and this has been firstly described by Kobasa et al. (41) as the collection of personality characteristics (particularly commitment, control, and challenge) to be able to cope and thrive under pressure. Early studies suggested that resilience is fixed as a trait and then it is developed into dynamic process, multidimensional and holistic perspective (outcome or processoriented) (9). The constructs of early studies are mainly focused on individual personalities such as optimism, self-efficacy, self-reliance, personal competence and later further developed into constructs in relation to the individual's social environment and external support systems such as friends, family, school as well as wider community connections. Resilience as a personalitytrait is best explained as the psychological

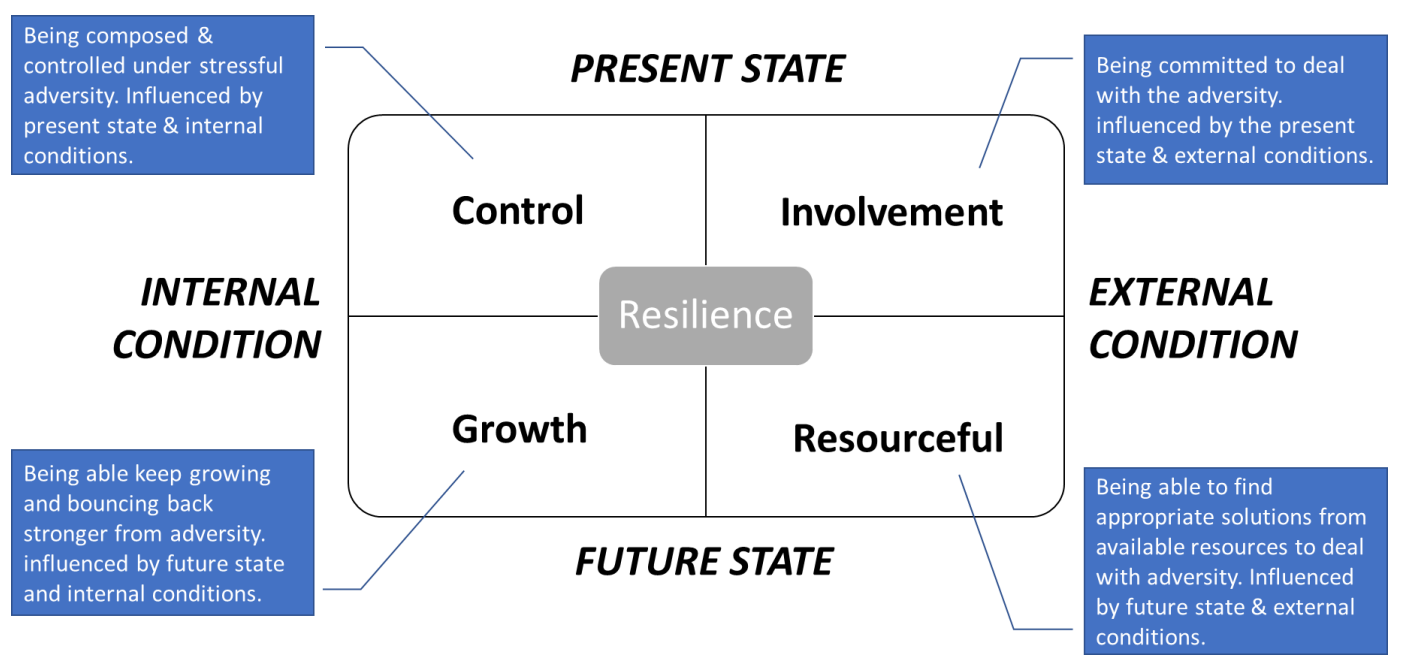

Figure 1: The integrated resilience model derives from 21 selected resilience scales 
attributes within the individual's self that improve coping ability and adaptability to stressors. It is something that is fixed and cannot be changed. However, resilience has shifted to outcome-oriented which is focusing on mental health after the individual has been exposed to stressors and adversity. It is something that can be developed, modified and can be predicted by resilience factors such as outside resources and internal resources (i.e. selfbeliefs). In recent years, resilience is being described as process-oriented approach. It is dynamic as a process and adaptable through consistent training and progress.

Based on the findings of our study, we proposed an integrated resilience model to conceptualise the relationships of the four emerging themes of resilience within the two continuums of state (present and future) and condition (internal and external) as shown in Figure 1. We organised the four themes within the framework in relation to these continuums. Based on Figure 1, control is influenced by present state and internal condition; involvement is influenced by present state and external condition; growth is influenced by future state and internal condition; resourceful is influenced by future state and external conditions. Based on this model, resilience is a combination of traits (exclusive and shared constructs), processes (state and condition) and outcomes (the four emerging themes). Starting from left to right, control and growth are coming from the internal condition of the human being while involvement and resourceful are determined by the external conditions. From top to bottom, control and involvement are influenced by the present state, while growth and resourceful are bound to future state (3). This model is unique because it addresses three main perspectives on resilience.

Considering operational definitions of the four emerging themes and their location in the developed model; Control is agreed to be defined as being composed and controlled under stressful adversity and it is influenced by the internal condition and present state. Involvement is defined as being committed to deal with adversity and it is influenced by the present state and external conditions. Resourceful is defined as being able to find appropriate solutions from available resources to deal with adversity and it is influenced by future state and external conditions. Growth is defined as being able to keep growing and bouncing back stronger from adversity and it is influenced by future state and internal conditions. Based on this model, resilience is a combination of the traits (exclusive and shared constructs), process (state and condition) and outcomes (the four).

\section{CONCLUSION}

This article proposes a unique framework because it combines the three main perspectives of resilience (traits, process, and outcomes) into a common concept of resilience. As a result, some or most of the themes or constructs which emerged from the current measurement of resilience are less developed, for instance "resourceful", "involvement" and "growth". Dozens of resilience scales are used in research, yet there is no specific scale that was developed and validated to measure resilience explicitly for health professionals or trainees. In addition, limited evidence that any scale is superior to another (38). Given the increasing interest in resilience of healthcare workers from major stakeholders (79), researchers are urged to develop a resilience scale specifically for healthcare workers by considering the proposed resilience constructs.

Considering the proposed resilience model, faculty members might want to emphasise the four resilience constructs during learning and teaching, for example, give a span of control for students to make contributions during learning sessions, get them involved with the daily routine of a doctor, provide adequate educational resources to facilitate 
their learning, and provide regular nonthreatening feedback for them to bounce back and grow stronger.

Infusing Resilience in the Assessment of Medical and Health Professions Education is another promising outcome of application of this new framework. Objectivity is so far the current approach in medical and health professions education to meet the quality needs and expectations of different stakeholders. Humanity is seldom highlighted to be considered alongside with this approach. Studies showed that medical students consider academic life particularly exams and tests are events that are most stressful; not only that, the extensive content to be learned but lack of time to revise were also among the most stressful events perceived by the students $(80-84)$. This indicates that something should be remedied in the current practice/ system of assessment. This mandates a strong call to rethink/reimagine the current framework of assessment practices in medical training so that it reduces stress and anxiety, thus promoting resilience development in medical trainees. In addition to huge efforts to objectifying activities of the assessment system to proof quality, it is a mandatory step to humanise assessment practice and infuse resilience constructs in this practice. Assessment systems should enhance students' capabilities by addressing these four resilience components; control, involvement, resourceful and growth. For example, provide students with clear descriptions of the assessment system to enhance their control, involving them in frequent formative assessment or mock exams for students to enrich their resourcefulness. Hence, students can grow based on these practices and be more resilient against adversities.

Correlating resilience and future performance is difficult not only because of inadequacies in the theory, concept and measurement of resilience itself but also because relevant, robust measures of outcome that can directly attribute to the effects of training have not been defined. Current efforts to reframe the resilience concept will guide researchers on refining the resilience scale and therefore may provide a more solid foundation for research on resilience.

\section{RECOMMENDATIONS}

This study proposes an integrated resilience model that is a promising model which can be used for different practical implications. It can be a basis for building new measurement scales, nurturing resilience in medical and health professions education, and infusing resilience elements in current assessment practices.

\section{ACKNOWLEDGEMENTS}

This work is a part of the research project that was funded by Fundamental Research Grant Scheme (FRGS: 203. PPSP.6171219), Ministry of Education, Malaysia.

\section{REFERENCES}

1. Greitens E. Resilience: hard-won wisdom for living a better life. Boston and New York: Houghton Mifflin Harcourt; 2015.

2. Sergeant J, Laws-Chapman C. Creating a positive workplace culture. Nursing Management (through 2013). 2012;18(9):14-9. https://doi.org/10.7748/ $\mathrm{nm} 2012.02 .18 .9 .14 . \mathrm{c} 8889$

3. Garcia-Dia MJ, DiNapoli JM, GarciaOna L, Jakubowski R, O'Flaherty D. Concept analysis: resilience. Arch Psychiatr Nurs. 2013;27(6):264-70. https://doi.org/ 10.1016/j.apnu.2013.07.003

4. Lee JH, Nam SK, Kim AR, Kim B, Lee MY, Lee SM. Resilience: a meta-analytic approach. J Couns Dev. 2013;91(3):26979. https://doi.org/10.1002/j.1556-6676 .2013.00095.x 
5. Windle G. What is resilience? A review and concept analysis. Rev Clin Gerontol. 2011;21(2):152-69. https://doi.org/10.1017/ S0959259810000420

6. Schwarz S. Resilience in psychology: a critical analysis of the concept. Theory \& Psychology. 2018;28(4):528-41. https://doi .org/10.1177/0959354318783584

7. Yusoff MSB. Promoting resilience and minimizing burnout. In: Henning MA, Krägeloh CU, Dryer R, Moir F, Billington $\mathrm{R}$, Hill AG, editors. Wellbeing in higher education: cultivating a healthy lifestyle among faculty and students. New York: Routledge; 2018. p. 82-105. https://doi .org/10.4324/9781315641539-9

8. Yusoff MSB. What does it take to minimise burnout and build resilience of healthcare learners? In: Lau CS, editor. Preparing healthcare learners for a changing world. Hong Kong: University of Hong Kong; 2019. p. 34-46.

9. Chmitorz A, Kunzler A, Helmreich I, Tüscher O, Kalisch R, Kubiak $\mathrm{T}$, et al. Intervention studies to foster resilience: a systematic review and proposal for a resilience framework in future intervention studies. Clin Psychol Rev. 2018;59:78-100. https://doi.org/10.1016/j.cpr.2017.11.002

10. Joyce S, Shand F, Tighe J, Laurent SJ, Bryant RA, Harvey SB. Road to resilience: a systematic review and meta-analysis of resilience training programmes and interventions. BMJ Open. 2018;8(6):e017858. https://doi.org/10.1136/ bmjopen-2017-017858

11. Bonanno GA, Diminich ED. Annual research review: positive adjustment to adversity-trajectories of minimal-impact resilience and emergent resilience. J Child Psychol Psychiatry. 2013;54(4):378-401. https://doi.org/10.1111/jcpp.12021
12. Underdahl L, Jones-Meineke T, Duthely LM. Reframing physician engagement: an analysis of physician resilience, grit, and retention. International Journal of Healthcare Management. 2018;11(3):24350. https://doi.org/10.1080/20479700.2017 .1389478

13. Leppin AL, Bora PR, Tilburt JC, Gionfriddo MR, Zeballos-Palacios C, Dulohery MM, et al. The efficacy of resiliency training programs: a systematic review and metaanalysis of randomized trials. PLOS ONE. 2014;9(10):e111420. https://doi.org/10 .1371 journal.pone.0111420

14. Caldeira S, Timmins F. Resilience: synthesis of concept analyses and contribution to nursing classifications. Int Nurs Rev. 2016;63(2):191-9. https://doi.org/10.1111/ inr. 12268

15. Bonanno GA. Loss, trauma, and human resilience: have we underestimated the human capacity to thrive after extremely aversive events? Am Psychol. 2004;59(1):20. https://doi.org/10.1037/0003-066X.59.1.20

16. Bonanno GAP, Mancini ADP. The human capacity to thrive in the face of potential trauma. Pediatrics. 2008;121(2):369. https://doi.org/10.1542/peds.2007-1648

17. Nucifora F, Langlieb AM, Siegal E, Everly GS, Kaminsky M. Building resistance, resilience, and recovery in the wake of school and workplace violence. Disaster Med Public Health Prep. 2007;1(S1):S33-S7. https://doi.org/10.1097/ DMP.0b013e31814b98ae

18. Zwack J, Schweitzer J. If every fifth physician is affected by burnout, what about the other four? Resilience strategies of experienced physicians. Acad Med. 2013;88(3):382-9. https://doi.org/10.1097/ ACM.0b013e318281696b

19. Ahern NR. Adolescent resilience: an evolutionary concept analysis. J Pediatr Nurs. 2006;21(3):175-85. https://doi.org/10 $.1016 /$ j.pedn.2005.07.009 
20. Epstein RM, Krasner MS. Physician resilience: what it means, why it matters, and how to promote it. Acad Med. 2013;88(3):301-3. https://doi.org/10.1097/ ACM.0b013e318280cff0

21. Elbarazi I, Loney T, Yousef S, Elias A. Prevalence of and factors associated with burnout among health care professionals in Arab countries: a systematic review. BMC Health Services Research. 2017;17(1):491. https:/doi.org/10.1186/s12913-017-2319-8

22. Squiers JJ, Lobdell KW, Fann JI, DiMaio JM. Physician burnout: are we treating the symptoms instead of the disease? Ann Thorac Surg. 2017;104(4):1117-22. https:// doi.org/10.1016/j.athoracsur.2017.08.009

23. Biksegn A, Kenfe T, Matiwos S, Eshetu G. Burnout status at work among health care professionals in atertiary hospital. Ethiop J Health Sci. 2016;26(2):101-8. https:/doi .org/10.4314/ejhs.v26i2.3

24. Rotenstein LS, Torre M, Ramos MA, Rosales RC, Guille C, Sen S, et al. Prevalence of burnout among physicians: a systematic review. JAMA. 2018;320(11):1131-50. https://doi.org/10 $.1001 /$ jama.2018.12777

25. Wisetborisut A, Angkurawaranon C, Jiraporncharoen W, Uaphanthasath R, Wiwatanadate P. Shift work and burnout among health care workers. Occup Med. 2014;64(4):279-86. https://doi.org/10.1093/ occmed/kqu009

26. Richardson GE. The metatheory of resilience and resiliency. J Clin Psychol. 2002;58(3):307-21. https://doi.org/10.1002/ jclp. 10020

27. Fox S, Lydon S, Byrne D, Madden C, Connolly F, O'Connor P. A systematic review of interventions to foster physician resilience. Postgraduate Medical Journal. 2018;94(1109):162-70. https://doi.org/10 $.1136 /$ postgradmedj-2017-135212
28. McCain RS, McKinley N, Dempster M, Campbell WJ, Kirk SJ. A study of the relationship between resilience, burnout and coping strategies in doctors. Postgraduate Medical Journal. 2018;94(1107):43-7. https://doi.org/10.1136/postgradmedj-2016 $-134683$

29. Cooke GP, Doust JA, Steele MC. A survey of resilience, burnout, and tolerance of uncertainty in Australian general practice registrars. BMC Medical Education. 2013;13(1):2. https://doi.org/10.1186/1472 $-6920-13-2$

30. Sood A, Sharma V, Schroeder DR, Gorman B. Stress Management and Resiliency Training (SMART) program among Department of Radiology faculty: a pilot randomized clinical trial. EXPLORE: The Journal of Science and Healing. 2014;10(6):358-63. https://doi .org/10.1016/j.explore.2014.08.002

31. Mache S, Baresi L, Bernburg M, Vitzthum K, Groneberg D. Being prepared to work in Gynecology Medicine: evaluation of an intervention to promote junior gynecologists professionalism, mental health and job satisfaction. Arch Gynecol Obstet. 2017;295(1):153-62. https://doi .org/10.1007/s00404-016-4223-6

32. Pliego JF, Wehbe-Janek $\mathrm{H}$, Rajab $\mathrm{MH}$, Browning JL, Fothergill RE. OB/GYN boot camp using high-fidelity human simulators: enhancing residents' perceived competency, confidence in taking a leadership role, and stress hardiness. Simulation in Healthcare. 2008;3(2):82-9. https://doi.org/10.1097/ SIH.0b013e3181658188

33. Runyan C, Savageau JA, Potts S, Weinreb L. Impact of a family medicine resident wellness curriculum: a feasibility study. Med Educ Online. 2016;21(1):30648. https://doi. org/10.3402/meo.v21.30648 
34. Sood A, Prasad K, Schroeder D, Varkey P. Stress management and resilience training among Department of Medicine faculty: a pilot randomized clinical trial. J Gen Intern Med. 2011;26(8):858-61. https://doi.org/ 10.1007/s11606-011-1640-x

35. Farquhar J, Kamei R, Vidyarthi A. Strategies for enhancing medical student resilience: student and faculty member perspectives. Int J Med Educ. 2018;9:1. https://doi .org/10.5116/ijme.5a46.1ccc

36. Passi V, Samantha J, Johnson N. A review of methods of developing resilience in undergraduate, postgraduate and continuing medical education; 2015. Available from: https://bemecollaboration.org/downloads/ 2358/BEME $\% 20$ Protocol $\% 202015 \% 20$ -\%20October\%202015.pdf

37. Kirch DG. Transforming admissions: The gateway to medicine. JAMA. 2012;308(21):2250-1. https://doi.org/10 $.1001 /$ jama.2012.74126

38. Windle G, Bennett KM, Noyes J. A methodological review of resilience measurement scales. Health and Quality of Life Outcomes. 2011;9. https://doi.org/ $10.1186 / 1477-7525-9-8$

39. Terwee CB, Bot SDM, de Boer MR, van der Windt DAWM, Knol DL, Dekker $\mathrm{J}$, et al. Quality criteria were proposed for measurement properties of health status questionnaires. J Clin Epidemiol. 2007;60(1):34-42. https://doi.org/10.1016/ j.jclinepi.2006.03.012

40. Ahern NR, Kiehl EM, Lou Sole M, Byers $\mathrm{J}$. A review of instruments measuring resilience. Issues in Comprehensive Pediatric Nursing. 2006;29(2):103-25. https://doi.org/ $10.1080 / 01460860600677643$

41. Kobasa SC, Maddi SR, Kahn S. Hardiness and health: a prospective study. J Pers Soc Psychol. 1982;42(1):168. https://doi.org/10 $.1037 / 0022-3514.42 .1 .168$
42. Bartone PT, Ursano RJ, Wright KM, Ingraham LH. The impact of a military air disaster on the health of assistance workers. J Nerv Ment Dis. 1989;177(6):317$28 . \quad$ https://doi.org/10.1097/00005053198906000-00001

43. Nowack K. Initial development and validation of a stress and health risk factor instrument. Am J Health Promot. 1990;4:173-80. https://doi.org/10.4278/ 0890-1171-4.3.173

44. Wagnild G, Young H. Development and psychometric. J Nurs Meas. 1993;1(2):16578.

45. Bartone PT. A short hardiness scale. Washington DC: Walter Reed Army Inst of Research; 1995. https://doi.org/10.21236/ ADA298548

46. Jerusalem M, Schwarzer R. Generalized self-efficacy scale. In: Johnston $M$, Wright $\mathrm{S}$, Weinman J, editors. Measures in health psychology: a user's portfolio cusal and control beliefs Windsor, England: NFERNELSON. Available at: http:// userpage.fu-berlin.de/ health/selfscal.htm; 1995. p. 35-7.

47. Block J, Kremen AM. IQ and egoresiliency: conceptual and empirical connections and separateness. J Pers Soc Psychol. 1996;70(2):349. https://doi.org/10.1037/ 0022-3514.70.2.349

48. Klohnen EC. Conceptual analysis and measurement of the construct of ego-resiliency. J Pers Soc Psychol. 1996;70(5):1067. https://doi.org/10.1037/ 0022-3514.70.5.1067

49. Gough HG. The California psychological inventory administrator's guide. Palo Alto, CA: Consulting Psychologists Press; 1987.

50. Hurtes KP, Allen LR. Measuring resiliency in youth: the resiliency attitudes and skills profile. Therapeutic Recreation Journal. 2001;35(4):333. 
51. Wolin S, Wolin S. Bound and determined: growing up resilient in a troubled family. New York: Villard; 1993.

52. Clough P, Earle K, Sewell D. Mental toughness: the concept and its measurement. In: Cockerill I, editor. Solutions in sport psychology. London: Thomson; 2002. p. 32-43.

53. Connor KM, Davidson JR. Development of a new resilience scale: the Connor-Davidson resilience scale (CD-RISC). Depression and Anxiety. 2003;18(2):76-82. https://doi. org/10.1002/da.10113

54. Kobasa SC. Stressful life events, personality, and health: an inquiry into hardiness. J Pers Soc Psychol. 1979;37(1):1. https://doi. org/10.1037/0022-3514.37.1.1

55. Rutter M. Resilience in the face of adversity: protective factors and resistance to psychiatric disorder. The British Journal of Psychiatry. 1985;147(6):598-611. https:// doi.org/10.1192/bjp.147.6.598

56. Lyons JA. Strategies for assessing the potential for positive adjustment following trauma. J Trauma Stress. 1991;4(1):93-111. https://doi.org/10.1002/jts.2490040108

57. Alexander C. The endurance: Shackleton's legendary antarctic expedition. London: Bloomsbury; 1998.

58. Friborg $\mathrm{O}$, Hjemdal $\mathrm{O}$, Rosenvinge $\mathrm{JH}$, Martinussen $M$. A new rating scale for adult resilience: what are the central protective resources behind healthy adjustment? Int J Meth Psych Res. 2003;12(2):65-76. https://doi.org/10.1002/mpr. 143

59. Oshio A, Kaneko H, Nagamine S, Nakaya M. Construct validity of the adolescent resilience scale. Psychological Reports. 2003;93(3_suppl):1217-22. https://doi.org/ $10.2466 /$ pr0.2003.93.3f. 1217
60. Sinclair VG, Wallston KA. The development and psychometric evaluation of the Brief Resilient Coping Scale. Assessment. 2004;11(1):94-101. https://doi.org/10 $.1177 / 1073191103258144$

61. Hjemdal O, Friborg O, Stiles TC, Martinussen $M$, Rosenvinge JH. A new scale for adolescent resilience: grasping the central protective resources behind healthy development. Meas Eval Couns Dev. 2006;39(2):84-96. https://doi.org/10.1080/ 07481756.2006 .11909791

62. Bromley E, Johnson JG, Cohen P. Personality strengths in adolescence and decreased risk of developing mental health problems in early adulthood. Comprehensive Psychiatry. 2006;47(4):315-24. https://doi .org/10.1016/j.comppsych.2005.11.003

63. Campbell-Sills L, Stein MB. Psychometric analysis and refinement of the ConnorDavidson resilience scale (CD-RISC): Validation of a 10-item measure of resilience. Journal Trauma Stress. 2007;20(6):1019-28. https://doi.org/10 $.1002 /$ jts. 20271

64. Bartone PT. Test-retest reliability of the dispositional resilience scale-15, a brief hardiness scale. Psychological Reports. 2007;101(3):943-4. https://doi.org/10.2466/ pr0.101.3.943-944

65. Sun J, Stewart D. Development of population-based resilience measures in the primary school setting. Health Educ. 2007;107(6):575-99. https://doi.org/10 $.1108 / 09654280710827957$

66. Ladd GW, Kochenderfer BJ, Coleman CC. Friendship quality as a predictor of young children's early school adjustment. Child Dev. 1996;67(3):1103-18. https://doi.org/ $10.2307 / 1131882$ 
67. Donnon T, Hammond W. A psychometric assessment of the self-reported youth resiliency: Assessing developmental strengths questionnaire. Psychological Reports. 2007;100(3):963-78. https://doi. org/10.2466/pro.100.3.963-978

68. Smith BW, Dalen J, Wiggins K, Tooley E, Christopher P, Bernard J. The brief resilience scale: assessing the ability to bounce back. International Journal of Behavioral Medicine. 2008;15(3):194-200. https://doi.org/10.1080/10705500802222972

69. Ungar M, Liebenberg L, Boothroyd R, Kwong WM, Lee TY, Leblanc J, et al. The study of youth resilience across cultures: lessons from a pilot study of measurement development. Res Hum Dev. 2008;5(3):166-80. https://doi.org/10 $.1080 / 15427600802274019$

70. Windle G, Markland DA, Woods RT. Examination of a theoretical model of psychological resilience in older age. Aging Ment. Health. 2008;12(3):285-92. https://doi.org/10.1080/13607860802120763

71. Linda R, Caltabiano M. Development of a new resilience scale: the Resilience in Midlife scale (RIM scale). Asian Social Science. 2009;5(11):39-51.

72. von Soest $\mathrm{T}$, Mossige $\mathrm{S}$, Stefansen $\mathrm{K}$, Hjemdal $\mathrm{O}$. A validation study of the Resilience Scale for Adolescents (READ). J Psychopathol Behav Assess. 2010;32(2):215-25. https://doi.org/10.1007/ s10862-009-9149-x

73. Damasio BF, Borsa JC, da Silva JP. 14item resilience scale (RS-14): psychometric properties of the Brazilian version. J Nurs Meas. 2011;19(3):131-45. https://doi.org/ 10.1891/1061-3749.19.3.131

74. Rossouw PJ, Rossouw JG. The predictive 6-factor resilience scale: neurobiological fundamentals and organizational application. International Journal of Neuropsychotherapy. 2016;4(1):31-45.
75. "internal-environment". Business Jargons. Available at: https://businessjargonscom/ internal-environmenthtml (cited Oct 2019).

76. External-Factors-Impacting-HRM-Video. Available at: https://study.com/academy/ lesson/external-factors-impacting-hrm. html\#lesson. (cited Oct 2019).

77. "current-state".

Bussiness Dictionary. Available at: http://www. businessdictionarycom/definition/currentstatehtml (cited Oct 2019).

78. "future". Collin Dictionary. Available at: https://www.collinsdictionary.com/ dictionary/english/future (cited Oct 2019).

79. Aziz N, Serafi AH. Increasing levels of test anxiety and psychological distress with advancing years of medical education. British Journal of Medical and Health Research. 2017;4(3):40-52.

80. Boparai JK, Gupta AK, Singh A, Matreja PS, Khanna PML, Garg P. Impact of test anxiety on psychomotor functions and satisfaction with life of medical undergraduates during second professional curriculum. Education in Medicine Journal. 2013;5(4):e6-e11. https://doi.org/10.5959/ eimj.v5i4.172

81. Yusoff MSB. Impact of summative assessment on first year medical students' mental health. Int Med J. 2011;18(3):172-5.

82. Yusoff MSB, Rahim AFA, Yaacob MJ. Prevalence and sources of stress among Universiti Sains Malaysia medical students. Malays J Med Sci. 2010;17(1):30.

83. Yusoff MSB, Yee LY, Wei LH, Siong TC, Meng LH, Bin LX, et al. A study on stress, stressors and coping strategies among Malaysian medical students. Int J Stud Res. 2011;1(2):45-50.

84. Wallace JE, Lemaire JB, Ghali WA. Physician wellness: a missing quality indicator. The Lancet. 2009;374(9702):1714-21. https://doi.org/ 10.1016/S0140-6736(09)61424-0 